\title{
Donde habita La Esperanza, la tierra la cuidan ellas
}

Fernanda Vallejo A.*

\section{Introducción}

$\mathrm{D}$ urante los meses de septiembre a diciembre del 2016, tuvimos la oportunidad de interactuar con un grupo de 15 mujeres que viven en la zona rural de la parroquia La Esperanza, Cantón Pedro Moncayo. Con ellas fuimos reconstruyendo el camino que han recorrido y fuimos identificando el rol que han jugado en el desarrollo de su parroquia. Ellas nos permitieron entrar en sus hogares y lugares de trabajo para recoger sus impresiones sobre el crecimiento económico que ha tenido su comunidad, sus implicaciones para la naturaleza, sus familias y para su propio desarrollo personal. La intención de esta investigación ha sido recorrer con ellas el camino desde la llegada de la agroindustria florícola a la zona, identificar los impactos en sus vidas de esta presencia, tratando de recoger las distintas perspectivas de cada una de ellas; y conocer más sobre las alternativas que ellas vienen impulsando en su comunidad.

Como resultado de este proceso hemos podido identificar que todas reconocen que la presencia de la agroindustria ha permitido que las mujeres rurales tengan acceso a ingresos que antes eran difíciles de conseguir. Sin embargo, también hay consenso sobre el "precio" que ellas y sus familias han tenido que pagar: alejamiento del hogar y de sus chakras. Independientemente de su ocupación actual, todas las mujeres entrevistadas identifican la agroecología como una alternativa sostenible para el desarrollo de su comunidad que le permite a las mujeres rurales desarrollar saberes y habilidades que ancestralmente han desempeñado (cuidado de la familia y naturaleza, saber "curar", cuidar la tierra y hacerla producir) y mejorar la economía familiar - al generarse un ahorro por el consumo de alimentos sanos producidos por ellas mismas y generar ingresos adicionales por la venta de sus productos en las ferias agroecológicas-.

A pesar de que los retos a futuro siguen siendo grandes (acceso a agua de riego, comercialización de los productos, etc.), las mujeres que formaron parte de esta investigación reconocen la necesidad de continuar trabajando para lograr una económica más justa y el sumak kawsay, para lo cual requieren de apoyo de los organismos del estado y otras instituciones que complementen las acciones que ellas vienen desarrollando.

* Antropóloga y educadora popular. Desde 1991 acompaña a comunidades indígenas y campesinas en la construcción de procesos autogestionarios. Forma parte del comité editorial de la Revista Biodiversidad Sustento y Culturas. Sistematización realizada con la colaboración de Susy Pinos, José Jarrín y Paúl Fernández. 


\title{
Las mujeres de La Esperanza: una historia de saberes y trabajos invisibilizados
}

\author{
"Mostrar que lo que no existe es, de hecho, producido como inexistente o sea, como una \\ alternativa no creíble a lo que existe" (Boaventura De Sousa).
}

El proceso dialogal con las mujeres de La Esperanza, nos condujo por un brevísimo recorrido por la historia de esos territorios. La versión menos vista, incluso por sus propias actoras, un escrito corto sobre lo inexistente, lo no creíble. Ese hacer cotidiano, completamente cierto, lleno de cuidados y de largas jornadas, no es percibido si quiera como inferior; es, sorprendentemente no mirado, no considerado como parte de la realidad que construye la historia de los lugares.

En esa misma línea, identificamos algunas constataciones adicionales, que nos permitirán explicar mejor, más adelante, cómo perciben estas mujeres diversas, su pasado, presente y futuro:

1. El lenguaje más importante no está en las palabras (en su mayoría escuetas y llenas de temor a expresarse, sobre todo entre las mujeres jóvenes o las mujeres que menos participan de procesos organizativos), está en su hacer, donde el registro del saber aparece en la acción.

2. Hay una incorporación naturalizada de los cambios impuestos, de los roles que la modernidad les va asignando, al tiempo que, paradójicamente, en ese hacer "naturalizado", se gestan las acciones de resistencia y persistencia que proveen opciones de vida campesinas, dignas en el marco de una apuesta por la producción agrícola como estrategia de autonomías mínimas.

3. La disponibilidad de dinero, en un determinado momento de la historia, se convirtió en un mecanismo de dignificación como seres humanos en el marco de las relaciones intersubjetivas dentro de la familia, particularmente frente al varón-jefe de hogar. El descubrimiento del manejo de dinero como herramienta de autonomía dentro del hogar, proporciona en un determinado momento, dos opciones claramente definidas: la del trabajo asalariado y la generación de iniciativas de ingreso a partir de sus tareas/ habilidades/saberes reproductivas y productivas (agropecuarias).

4. Para ninguna de las compañeras participantes, la ciudad es un anhelo por alcanzar; al contrario, se identifican retornos de migraciones temporales, o necesidad de opciones de empleo o de ingreso que les permita seguir en el campo.

\section{¿De dónde venimos?: somos indígenas, descendientes de "huasipungueras" de la hacienda}

Las historias, viejas y nuevas que nos fueron narradas, están marcadas por una memoria en común: la hacienda, esa larga formación económica semi-feudal que por más de dos siglos organizó las relaciones, la propiedad y la economía del país.

Mientras para la historia oficial, la independencia y constitución del Ecuador como república, son los hitos más relevantes en la construcción social del país; para el campesinado y los pueblos indígenas de la región interandina, el momento de cambio se produce tras las reformas agrarias (hace apenas cuatro décadas) cuando sus abuelos y abuelas finalmente, pudieron acceder a sus tierras, aunque éstas hayan sido marginales, las de peor calidad o de pequeña extensión.

"Antes vivíamos aquí arriba en esa hacienda, cuando vivíamos con mis abuelitos. Él trabajaba en la hacienda de la Pílsener, él era mecánico. Y bueno pues él en ese tiempo los hacendados les daban para vivir la casa y todo lo demás. Entonces de lo que yo me acuerdo vivíamos en esa hacienda. Ahi yo me crie, mis abuelitos usaban todo el terreno, bueno mi abuelita, porque mi 
abuelo se ocupaba de ir a la otra hacienda, a mantener la mecánica y ocupar las máquinas y venía a las 4 de la tarde. En cambio, mi abuelita si estaba en la casa y mi mamá también, ella cultivaba, tenía aves, tenía chanchos yo me acuerdo tenia de todo" (Elizabeth Mejía, 51 años).

"Mi madre, aparte de lo que ella servía, trabajaba en la hacienda, ella hacía en tiempo de las cosechas, él ordenaba que pele un quintal de mote y amanezca cocinando. Y también hacian la colada y el arroz de cebada, tenía que cargar la gente en pondos de barro de este porte, a la espalda. Así se salía a las cosechas en la hacienda, para poder tener los animales a todo campo, a todo dar, que se diga, eso sufría asi mi madre, mi padre. Trabajando así, para que nosotros poder tener los animales en los potreros de la hacienda" (María Teresa Cacuango, 74 años).

Dado que se trata de una institución de larga data, la hacienda constituye una herida cuyas huellas son visibles aún en el presente, y su importancia radica principalmente en haber configurado el patrón básico de la estructura de tenencia en la Sierra hasta la actualidad (Larrea, 2001).

La configuración de la hacienda tras la caída de la producción textil durante la colonia, se caracterizó por el acentuado control de la fuerza de trabajo indígena, la sujeción de la misma a través de relaciones extraeconómicas de coerción (concertaje, diezmos), la expropiación constante de tierras comunales fértiles y el desplazamiento de comunidades hacia los páramos; $\mathrm{y}$, una producción agrícola y textil destinada fundamentalmente al mercado local interandino ${ }^{1}$.

En el Ecuador se emitieron dos leyes de Reforma Agraria, entre 1964 y 1973, como mecanismo del Estado para sofocar la creciente movilización popular por el derecho a la tierra que, al igual que en toda Latinoamérica, se venía gestando. Mediante este mecanismo, pocos fueron los repartos de tierra por efecto de la lucha campesina, más bien se favoreció la entrega de parcelas dadas en usufructo por los terratenientes (huasipungos) y mecanismos de compra a través de créditos otorgados por el Estado y entidades vinculadas a la Iglesia Católica. Para el caso de La Esperanza,

“...las haciendas producían básicamente cereales. Para el año 1975, se ejecuta la parcelación de las Haciendas Guaraquí Grande y Mojanda y se entrega tierras a los comuneros y trabajadores de las haciendas, alrededor de 20 ha. Hacia los años 80, los pobladores de las parroquias y comunidades del cantón abandonaron paulatinamente el cultivo parcelario familiar para migrar hacia los sectores en los que empezaron a instalarse las florícolas" (Céspedes y Pachacama, 2012).

Las últimas recuperaciones de tierras por parte del campesinado ocurrieron hasta inicio de los años 90; es decir, poco antes de que se instalara la producción florícola en Cayambe y Pedro Moncayo. Muy poco tiempo para que el campesinado intentara una producción suficiente para generar renta, lo cual explicaría en parte, la facilidad con la que las empresas compraron lotes y transformaron a sus propietarios/as en jornaleros/as.

"Si bien es cierto, hubo más fuentes de trabajo y dejó dinero. Todo teníamos pero eso sí dinero no había. Pero fue un cambio brutal porque la gente dejó la tierra y fue a trabajar a la florícola. Incluso las haciendas que existían para la cebada y maices ahora se hicieron florícolas. Hubo más dinero pero las tierras fueron abandonadas. Pero ahora hemos concientizado que la tierra es lo que nos da de comer y no nos pide nada" (Blanca Aurora Morocho, 63 años).

"Más antes las haciendas sembraban, las gentes sembraban. Ahora no ve, todos los terrenos ya se van "retaceando", cogiendo los herederos, cada vez menos para que trabaje cada persona" (Carmen Alcocer, 49 años).

1 Este modelo aparece como predominante en la Sierra Centro-norte como región medular a partir de la cual la clase terrateniente expande o constriñe sus espacios de control político-económico. En relación a las particularices del modelo en la Sierra Sur, ver Ospina (2003). 
"Cuando inicialmente llegaron, en especial ciudadanos de Colombia a hacer las adquisiciones de los terrenos aqui en el sector. Ofrecian que se yo, si un terreno costaba unos 10.000 dólares, hablando así, ellos decían yo te doy 20.000 y yo te llevo para que trabajes conmigo. O sea aparte de eso les compraban la mano de obra a los campesinos" (Jaqueline Lema, 40 años).

\section{Una pequeña herencia: la tierra}

Los testimonios recogidos nos hablan de estos temas, aunque de manera escueta, como si fuese "obvio" que así ocurriese y si bien no abundan en detalles, nos permiten constatar varias cosas:

Recuperar la tierra es motivo de orgullo: saberse dueñas de un pedazo gracias a sus abuelos que sufrieron la humillación del trabajo servil y se emanciparon mediante lucha, genera una auto afirmación como ciudadanas con ciertos derechos civiles, aunque exista al tiempo, una conciencia de una ciudadanía de segunda clase: "Mi abuelito y abuelita ganaron esto como esclavos, como wasicamas. Eso heredó a mis papás" (Cristina Toapanta, 28 años).

A diferencia de las tendencias nacionales, las mujeres de La Esperanza con quienes conversamos son, en su mayoría, propietarias de sus tierras: Ya sea por herencia o por compra, las mujeres son propietarias o co-propietarias de sus tierras. "Mi esposo, él como mi esposo, Segundo Francisco Lema y dice, "señora”, la señora soy yo (risas)" (María Teresa Cacuango, 74 años).

Las unidades productivas campesinas en la zona, se constituyen a partir de varios pedazos dispersos en el territorio, algunos son herencia de las mujeres; otros son herencia de los hombres y siempre hay parcelas adquiridas mediante compra bajo la figura de bienes mancomunados.

"Esto es que ha heredado mi esposo de los antepasados, ha heredado de sus papás: de mis suegros y mis suegros vuelta ya le dieron a sus hijos y asi a nosotros nos toca vuelta dar a nuestros hijos. El título es de mi esposo pero yo trabajo la tierra, yo la disfruto" (Laura Cuzco, 48 años).

"Como somos casado, está primerito el nombre de esposo y luego el mío" (Carmen Alcocer, 49 años).

"Es de los dos esposos que compraron dentro del matrimonio. Ahora decimos no es nuestro, porque ya lo dividimos para nuestros hijos. (Ella dice que lo disfruta más porque le gusta trabajar en el campo y es quién lleva las riendas de lo que se produce)" (Blanca Aurora Morocho, 63 años).

Para la mayoría de compañeras -incluso aquellas jornaleras asalariadas en las florícolas-, tener tierras es vital, es su plataforma vital, a partir de la cual se proyectan socialmente. Es su garantía de soberanía alimentaria, es su ahorro de jubilación cuando salgan de las flores, o su capital de inversión cuando decidan instaurar un trabajo autónomo.

"Sí, es bastante diferente porque ya con la agroecología ya siembro alguna hortaliza y ya tengo para mi alimentación misma y de mis niños. De las que no tienen terreno. Las que no siembran la agroecología, es todo comprado, todo químico y no se ayudan en nada ecológicamente" (Maribel Guachamin, 28 años).

"[...] lo que se está haciendo ahorita es nuevamente que la gente vuelva al campo. Hay personas de la tercera edad que ya salen rechazadas de los trabajos floricolas y ya no saben qué hacer. Entonces lo que se ha hecho en lo personal, se les ha ido motivando para que sigan cultivando y no vayan y estén en una esquina sentados, mendigando que alguien les de algo, sino que se den valor y sigan siendo productores" (Jaqueline Lema, 40 años). 
He aquí otro aspecto importante: el trabajo extra-finca, les proporciona liquidez y renta suficiente como para comprar más lotes de tierra, y realizar inversiones productivas con miras a una producción autónoma (agroecológica), pero la perspectiva mayoritaria no es la de permanecer como asalariadas, sino de capitalizarse para producir en sus tierras. Su tierra es su ahorro, su base, su lugar de retorno, su medio de producción.

\begin{abstract}
"Antes yo tuve que salir a trabajar a las plantaciones porque no habia otro sistema de desenvolverse económicamente así como mujer, entonces y a de que apareció esto de la agroecología, ya tenemos el sistema del agua. Me desenvuelvo lo que es la alimentación, económicamente lo que me sobra vendo y tengo para las necesidades de la casa" (Laura Cuzco, 48 años).

"La producción de flores (contaminante) es una necesidad, pero porque no hay otra fuente de empleo. Por ejemplo, si a mi me dijeran si quiero ir a trabajar produciendo hortalizas yo me voy para allá, pero no hay otra fuente. La soberanía alimentaria se ve en la casa, viendo lo sano para comer" (Cristina Toapanta, 28 años).
\end{abstract}

Ahora bien, tener tierra es un mínimo paso hacia una vida más autónoma; sin embargo, no es suficiente pues no ha constituido una garantía de acceso a crédito productivo, por ejemplo; tampoco les garantiza la representación directa en organizaciones locales de riego o acceso a servicios como agua de consumo. Existe, además, un comportamiento que más allá de la norma jurídica, opera y se aplica por efecto de la tradición y tiene que ver con el peso de las decisiones sobre los predios que se asigna a los varones (Flores, 2011, en: Hidalgo y Laforge, 2011).

Pese a todo lo expuesto hasta ahora, también existen mujeres sin tierra, con muy pocas posibilidades de acceder a un lote, a menos que sea un minifundio dado por herencia. El proceso especulativo que sobre el suelo se desencadenó con la industria florícola, sumado al difícil acceso a crédito, mencionado anteriormente, muestran una perspectiva nada alentadora para las generaciones más jóvenes quienes enfrentan el desafío de mantenerse en su territorio, pero no tienen más opción que la vinculación laboral en la florícola, y ante la perspectiva de su cierre, vislumbran la debacle económica de las familias en la zona.

"Todo es un círculo porque todos dependemos entre nosotros, si cierran las flores muchas personas se quedarian sin trabajo y sin que sean pagados" (Paola Toapanta, 25 años).

“[...] esta propiedad en la que estamos es arrendada, no hemos podido hacer la adquisición de las tierras. Porque otro aspecto negativo de la implementación de las florícolas es el encarecimiento de las tierras acá" (Jaqueline Lema, 40 años).

Como veremos más adelante, la producción agroecológica, por su carácter intensivo, diversificado y con minimización de riesgos, es visto como la alternativa en este escenario.

\title{
La impronta de la hacienda en los modos de hacer agricultura, en la distribución del trabajo y en las relaciones sociales.
}

La construcción de los territorios ha operado gracias a las interacciones entre sujetos y actividades productivas; pero, sobre todo, por la puesta en práctica de estrategias operacionales que se apoyan sobre la cultura, la historia. La movilización del "saber-hacer", los fenómenos de aprendizaje colectivo, los modos o formas de cooperación y de asociación entre los actores y las prácticas de adaptación que se desarrollan en escala local.

Para las mujeres con quienes conversamos, la hacienda, aun siendo una institución de dominación y oprobio, no logró desmontar relaciones sociales de producción de más larga data. De hecho, las usó en su beneficio. 
En los testimonios de las mujeres mayores queda clara la huella de un modo sincrético de hacer agricultura, de relacionarse con el territorio como una unidad mayor, más allá de las áreas de cultivo. El uso y manejo vertical de los ecosistemas y microclimas: Las zonas altas, de páramo, para el pastoreo, la recolección de plantas medicinales y el cuidado de los ojos de agua. Las zonas altas para el cultivo de papas, tubérculos y leguminosas de altura, y las zonas bajas para el maíz, fréjol y frutales.

"[...] nosotros por ejemplo tenemos en el páramo la reserva natural, la flora y fauna intactos. Nosotros cuidamos que no vayan a quemar, solo hay unos que son sordos, van arar, van a dañar la paja, tumban los arbolitos, que atraen la lluvia" (María Teresa Cacuango, 74 años).

"Desde que aparecieron las florícolas el cerro comenzó a secarse, ultimadamente ya no veo tanto, pero hubo un tiempo que ya no hubo nada de hielo, entonces eso si nos causaba mucha preocupación, dijimos ya nos vamos a morir secos" (Laura Cuzco, 48 años).

De sus abuelas heredaron el saber del manejo de animales menores, las semillas, los ciclos y tiempos de siembra, incluyendo el conocimiento de la luna y otras "señas" que la naturaleza muestra para determinar el mejor momento para una labor cultural. Junto con ello, los momentos festivos de comunión con la tierra y con la comunidad, tiempos sagrados que se mantienen cada año. Y claro está, los platillos con los productos disponibles según se corresponden a cada ciclo.

"En la agricultura mis padres me decían que era mejor sembrar con la luna, el maíz salía bonito con la luna creciente y que con la llena no vale sembrar" (Elena Alcocer, 63 años).

"Desde nuestros abuelitos, los mayores nos han enseñado que hay que sembrar viendo la luna cuidando las fechas" (María Suarez, 45 años).

"Hubo un cambio bien bueno, porque venimos a comer productos que sembrábamos; sano. A recordar, digamos. Volvimos a rescatar lo que era antes, productos sanos, buenos, sabemos lo que comemos y qué contienen todos los productos" (Blanca Aurora Morocho, 63 años).

Se trata de una agricultura de soberanía alimentaria, una agricultura para la vida, donde todo se utiliza, nada se desperdicia, donde todos los seres del universo se nutren y cuidan unos a otros: las semillas, la tierra, los animales, las personas, los ancestros y ancestras. Y en el centro de esa vida que se garantiza y se perpetúa, las mujeres con sus saberes y su trabajo interminable, que no se ven, no se valoran, se dan por sentado.

"Cuando uno tiene que sembrar o desherbar, se llama a los vecinos y vienen a ayudar sin el compromiso de cuánto se les va a pagar. Por ejemplo, la vecina ya nos ve que estamos trabajando viene a ayudar" (Cristina Toapanta, 28 años).

"Ahí también salimos a la minga (forma de trabajo comunitario), así como se paga del agua potable también se paga del agua de riego. Salimos a trabajar los dos con mi esposo, como estamos en la tercera edad ambos, trabajamos los dos para que sea tomado en cuenta 2 por 1" (María Teresa Cacuango, 74 años).

"Antes cuando iban hacer algo en la casa, todo el mundo llegaba a colaborar a ayudar y así mismo habia algo en otra parte, íbamos y colaboramos. La vecina está haciendo algo, tenemos que ayudarle y vamos" (Elizabeth Mejía, 51 años).

Cuando hablan de su hacer, son escuetas, les cuesta identificarlo como saber. Se perciben custodias celosas del cuidado, pero no le encuentran valor mayor a esa tarea vital. 
"Me levanto a las 5, 5 y media, a veces a las 4, asi a hacer el desayuno, ya les mando a mis chicas que se van a trabajar. Se van desayunando, de ahi luego les levanto a mis nietos que se vayan a la escuela. Les hago vestirse, todo eso. Les mando a la escuela a los chicos y de ahi ya me pongo a mis labores de la casa. Empiezo por los cuyes a cortar la hierba, a dar de comer a los chanchos, de ahi me llevo a las vacas, de ahi es eso como las 11 de la mañana, les amarro a las vacas por ahi y regreso hacer el almuerzo. Hago el almuerzo, ya llegan hasta eso mis guaguas, entonces les sirvo el almuerzo, de ahi otra vez les digo que se pongan hacer los deberes cada quien, a sus casas, porque si no se pelean. Entonces les hago que se pongan hacer los deberes. Entonces ya me voy al ganado. Le traigo al ganado a la casa para que estuvieran ya guardados. De ahi les reviso que ya han hecho los deberes, sino de ahi les castigo. Les doy algún castigo así para que me ayuden asi para afuera. Entonces ya ellos como no les gusta mucho eso de hacer cosas en el campo. Entonces creen que es un castigo. Pero entonces yo les digo, asi tienen que aprender, yo asi crecí. Entonces les hago que me ayuden... asi las cosas... Ya asi hasta eso ya se hace la hora que llegan las mamás y les entrego a sus hijos. De ahi yo continuo con el resto de asegurar mis animales, doy otra vez hierba a los cuyes, a los chanchos y ya me llega la hora de hacer la merienda, eso como a las 7, 8 de la noche, empiezo otra vez, vuelta con la merienda. De ahi si ya nos vamos a descansar cada quien en sus cuartos" (Laura Cuzco, 48 años).

Resulta evidente aquí una necesidad imperiosa de trabajar alrededor de hacer visible ese inmenso ámbito de la economía del cuidado, que subsidia a toda la sociedad y por tanto debe quedar oculto a los ojos de sus propias ejecutoras, pues constituye un nicho potencial de rebelión y demanda.

Tal como analizan en un estudio similar de la Asamblea de Mujeres Populares y Diversas del Ecuador:

"Para las mujeres, conjugar el trabajo de la casa con el del campo supone plantearse un sin número
de asuntos: ¿qué cocinar?, ¿cuándo? o ¿con qué productos?, ¿cuánto gastar en la alimentación de
la familia?, ¿cómo obtener el dinero?, o ¿qué comerán nuestros hijos e hijas cuando se encuentran
fuera de casa? También ¿qué productos sembrar?, ¿cuándo hacerlo? y ¿con qué semillas?, ¿cuándo
será la cosecha?, ¿dónde conseguir el crédito y los recursos para la siembra, el agua, la tierra, el
abono, las semillas?” (Altamirano et al., en: IEE y ONU, 2013).

Asuntos todos, de responsabilidad de las mujeres, cuya gestión y ejecución presuponen la invisibilización de: a) un cúmulo importante de saberes agrícolas, culinarios, medicinales, ecológicos, sociales y de crianza; $y, b$ ) un extenuante trabajo que demanda doble o triple jornada para completarse (Ibíd.: 23-24).

Cuando tratamos este tema, las mujeres lo señalan, lo identifican, pero de manera naturalizada, y cuidándose mucho de parecer quejumbrosas o "revanchistas" respecto al trabajo masculino en sus entornos.

"El trabajo de los hombres es más valorado porque tal vez traen algo más económico, lo que es el dinero así. Entonces piensa que en la casa no hemos hecho nada: "no veo hecho nada" (me dice); le digo: "iqué pena que usted no vea, pero yo si veo, porque de ahi como, de ahi comemos" -le digo- y usted no se da cuenta de eso" (Laura Cuzco, 48 años).

"El hombre descansa un poquito más porque se levanta más tarde y las mujeres ya estamos trabajando, igual se acuestan temprano y uno tiene que lavar y acabar de arreglar las cosas" (María Suarez, 45 años).

Otro aspecto relevante en este corto ejercicio de memoria histórica, es el hecho casi implícito de que la conquista de la tierra, no trajo consigo la conquista de mejores relaciones de género. El régimen de hacienda heredó también una rígida división sexual del trabajo y todos sus mecanismos sociales de control para que se mantenga. Más allá de la desigual y naturalizada 
distribución de tareas, se produjo una apremiante necesidad de circulante, pues la producción por medios propios requería de la monetización de la producción y de las relaciones. En ese contexto, donde el campesinado en general no constituye un sujeto de crédito para el Estado, donde el Estado titulariza al "jefe-masculino" de hogar como sujeto de interacción, el acceso al dinero se convierte en un mecanismo más de subyugación femenina. El Estado no interactúa con las mujeres, el Estado no reconoce la titularidad de las mujeres como comuneras, el Estado no otorga créditos a los campesinos -menos aún a las campesinas- y con el Estado, todas las entidades públicas, privadas e incluso la cooperación al desarrollo.

Ocurre entonces, que las mujeres son objeto de violencia doméstica por no constituirse en sujetos generadores de dinero a través de sus actividades. Si el campesinado constituye una ciudadanía de segunda clase, las mujeres campesinas, ni siquiera llegan a ser vistas como ciudadanas.

Las mujeres de La Esperanza narran sus historias mencionando casi de "contrabando" este hecho violento y socialmente avalado. Nos describen la necesidad de tener dinero, aprendida de sus madres, como el principal consejo de supervivencia. De él se desprenden historias de migración a la ciudad para trabajar como empleadas domésticas, o el aprendizaje del comercio de productos en mercados, como mecanismos de obtención del preciado bien, que les libera al menos, de la humillación doméstica y la total dependencia de los hombres de su entorno.

"[...] hemos sido un poco maltratadas por el hecho de ser mujeres. Hace tiempo si nos humillaban por el hecho de ser mujeres, pero ultimadamente, desde que pareció la agroecología, ya nos defendemos, ya no nos dejamos maltratar. Incluso me pegaba mi esposo, decía que no le ayudo para nada, que no le ayudo así incluso económicamente para la casa. Entonces como tenia así mis hijos chiquitos, no podía salir a trabajar, en ese entonces no habia, asi para hacer agroecología. [...]. Mis padres siempre trabajaron la agricultura, los dos, a veces mi papá salía así a trabajar por lejos, para traer asi dinero. Pero mi mamá siempre trabajó en la agricultura, mi papá también le humillaba. [...] De la agricultura nunca me ha hecho falta un hombre aqui en la casa, le hago de todo" (Laura Cuzco, 48 años).

Todo lo descrito nos permite también explicarnos un aspecto particularmente curioso de la historia del territorio, cuando de la mirada de las mujeres se trata: la organización.

\section{La organización y las mujeres líderes}

La Esperanza tiene un abigarrado tejido organizativo territorial, en la parroquia persisten las comunas campesinas (a contrapelo de la urbanización forzada a la que se han visto sometidos), esa estructura básica que aglutina familias, territorios comunales, relaciones recíprocas, fundadas en el trabajo colectivo como mecanismo de producción y reproducción de la vida. En este territorio, durante la lucha por el acceso a la tierra, se configuro una importante federación campesina denominada UCOPEM - Unión Campesina de Organizaciones de Pedro Moncayo. Al que se adscribían estas comunas y que, con la llegada de las flores y la contrarreforma agraria de 1994, fue desdibujando su rol hasta perder representatividad. En la historia reciente, hace una década apenas, las organizaciones de regantes del territorio, entre ellas la Junta de La Esperanza, impulsaron una dura lucha por el acceso al agua de riego, en vista de que la administración municipal, además de ineficiente, solo respondía a los intereses del modelo de concentración de las empresas florícolas. Fruto de esa lucha, las organizaciones lograron el control del canal y asumieron de hecho, la administración y distribución del agua.

Cuando indagamos su sentido de pertenencia a alguna organización, su referencia es muy escueta. Si miramos el funcionamiento cotidiano de éstas en La Esperanza, es posible aventurar una explicación a partir del hecho simple de que las mujeres son partícipes marginales de las 
decisiones en esta zona. Las juntas de regantes, los cabildos comunales, están mayoritariamente conformados por hombres, las decisiones sobre el riego son absolutamente masculinas; las mujeres apenas acatan y ejecutan esas decisiones.

Según sus percepciones, forman parte de distintas organizaciones: Junta de Regantes, Feria de Agroecología. Indican que ser mujer y participar en organizaciones significa tener muchas responsabilidades. Para una de ellas esto ha significado que, “...me siento mejor, antes nos ignoraban, me siento más, que puedo desenvolverme económicamente y ya no me siento humillada por mi esposo" (Laura Cuzco, 48 años).

Existe una clara diferencia respecto al sentido de pertenencia entre quienes producen en sus chakras para vivir y quienes tienen trabajo asalariado en las flores. Tres de las mujeres entrevistadas en este grupo trabajan en florícolas, dos de ellas se consideran mestizas. Ninguna forma parte de una organización y no respondieron a la pregunta relacionada con la participación de las mujeres en las organizaciones y en roles de liderazgo. Sin embargo, una de ellas señaló que debería haber al menos una mujer en el gobierno local para que atienda y entienda las necesidades del resto de las mujeres trabajadoras, sobre todo para facilitar el acceso a servicios médicos. Cuentan con terrenos y casas propias y en uno de los casos es de sus padres.

En contraste, la organización de productoras agroecológicas de la feria, además de estar básicamente compuesta por mujeres, constituye un espacio donde son ellas quienes decidieron estar para generar alternativas a sus búsquedas de comercialización de su producción, y son ellas quienes discuten sus problemas y definen estrategias de salida. Esta organización germinal, muestra aún muchas limitaciones políticas e ideológicas, pero es el espacio más claramente suyo del que forman parte.

"Dentro de las tareas realizadas aqui en la comunidad, debo manifestar que al pertenecer al grupo de productores y al ser uno, somos los pioneros en el tema de agroecología y en la producción acá. Es bastante fructifero porque se ha podido colaborar, se ha podido ir cambiando la mentalidad de personas que lamentablemente por su trabajo en las floricolas dejaron abandonando el campo. $Y$ en lo que se está haciendo ahorita es nuevamente que la gente vuelva al campo" (Jaqueline Lema, 40 años).

En tanto los saberes no son cosas, sino entramados de relaciones que se tejen en los territorios, la historia de nuestras mujeres nos habla de un breve momento al recuperar la tierra, en el cual empezaba a tejerse un modo sincrético, colonizado y patriarcal, pero al mismo tiempo germinal de formas autónomas de producir, que rápidamente se vio invadido por un nuevo momento de modernización del agro capitalista.

\section{Las flores: el capitalismo que se instala en nuestro territorio, en nuestros cuerpos, en nuestro tiempo, en nuestros saberes, en nuestras relaciones}

\section{Una introducción necesaria}

El espacio es una instancia producida socialmente en función de la reproducción física y social, apropiación, explotación, intercambio y manejo (control) en torno a un territorio (Ospina 2003: iv). En tanto producto social, el espacio está sujeto a la construcción de lo que Agudo (2000) denomina "representaciones sociales" como formas particulares de construcción social, que contribuyen a promover y orientar las acciones de los actores sociales (sus posiciones y relaciones). Este ámbito subjetivo que dota de historicidad al territorio y contribuye a la definición de identidades, es el que mejor nos permite contextualizar las reflexiones del grupo de mujeres, con quienes compartimos. 
Tanto las reformas agrarias, como la política de innovación tecnológica para modernizar la producción lechera, produjeron cambios importantes en el paisaje, y en el saber agrario campesino. La revolución verde hacía su aparición de la mano del Estado y de la cooperación al desarrollo. Sin embargo, es con la instalación del agro-negocio florícola que el territorio experimenta un salto definitivo a la privatización de la agricultura y la monetización de las relaciones. A fines de los 80 's, con inversiones y amplia asistencia técnica, provenientes sobre todo de Holanda, Israel y Colombia, primero Cayambe y luego Pedro Moncayo (donde se encuentra La Esperanza), se trasformó en la zona de mayor producción florícola y desarrollo capitalista del área interandina².

En 2005, el rubro flores alcanzó una venta de 370 millones de dólares aproximadamente 90 mil toneladas, lo cual con respecto a 2004 representó un crecimiento de $4.3 \%$ (Breilh, 2005), que se relaciona a la aplicación del ATPDEA ${ }^{3}$. Se estima que en este mismo período donde se registran picos más altos de producción y mercados, esta agroindustria capturaba un promedio de 13 trabajadoras por hectárea, aproximadamente entre el 25\% y el $30 \%$ de la población (en su mayoría mujeres) (Brassel et al., 2008).

Estos brevísimos datos permiten ubicar la radicalidad de los cambios que operaron en la zona, las promesas de la modernidad, el imaginario de un empleo fijo que genere un salario mensual, la posibilidad de ampliar el consumo, la creciente oferta de servicios básicos, por mencionar algunos aspectos, constituyeron mecanismos muy eficaces de colonización.

Las flores trajeron nuevas tecnologías y una utilización sin precedentes de agroquímicos. Trajeron un trastocamiento radical de los órdenes domésticos, se apropiaron del tiempo de las mujeres, trajeron afectaciones a su salud tanto por la exposición indiscriminada a pesticidas, como por el sobre trabajo que asumieron "naturalmente" en la empresa y en la casa. Trajeron conflictos familiares, conflictos laborales. Pero todo eso sería, el precio a pagar por la mayor posibilidad de que las niñas terminen sus estudios, se cuente con agua de consumo en las casas, luz, teléfono, vías adoquinadas, internet.

Todos estos temas son mencionados por las mujeres, pero su mirada no se pregunta, solo asume los hechos como dados; algunos de ellos, como la afectación de la salud o la merma en el vínculo de cuidado con los hijos, son acaso los más sentidos, los que más les lleva a plantearse otras opciones. La escisión de sus vidas, donde el trabajo es un mundo que no les pertenece, un espacio prestado pero necesario, con unas prácticas que no comparten, pero acatan. Es claro para aquellas que trabajan en las flores, que esa agricultura y ese modo de vida contamina, depreda y enferma; mientras que su espacio doméstico, su agricultura y su vida comunitaria, son los reductos de cuidado y preservación de la vida.

No contaminar el aire con químicos, plásticos. Incorpora lo que es materia orgánica en el suelo, asi todas esas cosas. Pienso yo que es una manera de cuidar a la Pachamama que es la tierra que nos alimenta. Laura Cuzco, 48 años.

El ejercicio actual del poder hegemónico, además de ser global, es fruto de un acumulado y un continuum colonizador que no se detiene. Para el caso latinoamericano, se expresa la ocupación concreta de territorios, imposición de matrices productivas, desmembramiento de bases materiales y sociales de reproducción, y consolidación sostenida de una concepción del mundo. La agro-industria florícola, viene a instalar la globalización, inaugurando en la región interandina un nuevo y más eficaz momento del capitalismo.

2 Desde hace más de más 25 años se dio inicio a las primeras empresas florícolas en los cantones: Cayambe (incluyendo las parroquias: Ayora, Juan Montalvo, Cangahua, Otón y Ascázubi); y el cantón Pedro Moncayo en las parroquias: Tupigachi, la Esperanza y Malchinguí.

3 Ley de Preferencias Arancelarias Andinas y Erradicación de la Droga, mejor conocida como ATPDEA (siglas en inglés para "AndeanTrade Promotion and Drug Eradication Act") fue un sistema de preferencias comerciales por los cuales Estados Unidos otorgaba acceso libre de aranceles a una amplia gama de las exportaciones de cuatro países andinos: Bolivia, Colombia, Ecuador y Perú, como una compensación económica por la lucha contra el tráfico de drogas. 
Un aspecto importante de esta investigación era poder identificar los cambios más significativos ocurridos desde la llegada de la industria florícola a la parroquia, desde la visión de este grupo de mujeres, todo lo hasta ahora descrito, se expresó durante el segundo taller mantenido con el grupo.

Todas identifican cambios en la comunidad luego de la llegada de la florícola, hay coincidencia en decir que las florícolas han traído más dinero a la comunidad. Sin embargo, también han causado una mayor presencia de basura, químicos y contaminación. Además, más enfermedades en las personas y el abandono de la tierra pues la gente ha dejado de producir para ir a trabajar dentro de las florícolas.

El grupo de las más jóvenes señala que las florícolas trajeron más trabajo, lo cual disminuyo la migración a Quito, las mujeres ahora llevan dinero al hogar; pero las "familias y los terrenos están botados", hay más madres solteras y menos estabilidad familiar, ha aumentado la contaminación del cuerpo y del ambiente. Indican que las florícolas no han trabajado para las comunidades.

En tal sentido, la modernidad es una forma cultural particular que se erige como universal, y que permite la consolidación y expansión tanto de una visión del mundo, como de prácticas específicas que hacen de la economía occidental una esfera autónoma y dominante de la vida social (Escobar, 1995). Como todo mecanismo ideológico colonial, su éxito radica en su naturalización como modelo de funcionamiento social y cultural. Naturalizar una visión del mundo supone su inmutabilidad consustancial, construye un imaginario sin historia y sin lugar.

"La expresión más potente de la eficacia del pensamiento científico moderno -especialmente en sus expresiones tecnocráticas y neoliberales hoy hegemónicas es lo que puede ser descrito literalmente como la naturalización de las relaciones sociales, la noción de acuerdo a la cual las características de la sociedad llamada moderna son la expresión de las tendencias espontáneas, naturales del desarrollo histórico de la sociedad. La sociedad liberal industrial se constituye -desde esta perspectiva- no sólo en el orden social deseable, sino en el único posible. Esto le da la capacidad de constituirse en el sentido común de la sociedad moderna" (Lander 2000:11).

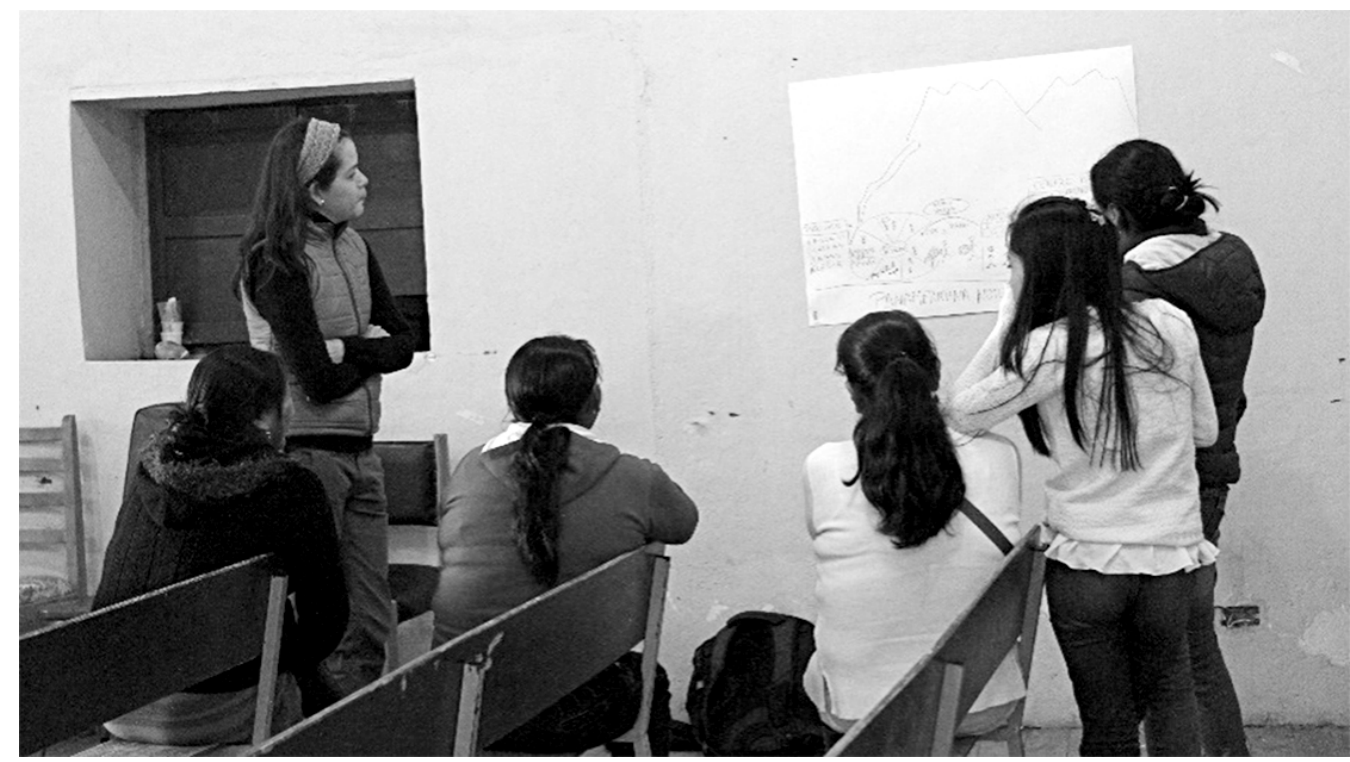

FOTO 1. Segundo Taller. 
Durante el segundo taller que tuvimos, conversamos sobre cómo cambiaron sus vidas y su entorno desde la llegada de las florícolas. Los cambios más significativos que ellas han percibido están a varios niveles:

\section{A nivel personal}

Un tema recurrente en la conversación fue el cambio de vestimenta, las participantes indicaron que las mujeres vestían siempre el traje tradicional pero que el trabajo en las florícolas y el acceso a más efectivo fueron promoviendo el uso de otras prendas, especialmente los pantalones, entre las mujeres jóvenes. Las mujeres de mayor edad, recordaron que cuando eran pequeñas sus madres las castigaban si no usaban falda. Ellas mantuvieron el uso de la prenda incluso durante los períodos en que migraban a la capital, ya sea por continuar sus estudios o por trabajo.

Las mujeres no identificaron una razón por la cual el trabajo en las florícolas fue cambiando su vestimenta, pero se entiende que facilitar las labores agrícolas dentro de las plantaciones y el uso de equipos de protección para la aplicación de agroquímicos pueden ser causales del cambio en la vestimenta. Tampoco se explicitó si las mujeres más jóvenes que no usan la falda tradicional se sienten mejor por eso o si la elección del uso de pantalones ha sido una decisión consciente de las jóvenes y una expresión de su propio gusto e identidad.

Queda con el grupo una asignatura pendiente de reflexión en relación a la colonialidad ejercida por el impacto modernizador de la agro-empresa sobre la estética, los patrones de belleza y de moda en la población local, de manera particular, las mujeres.

Sin embargo, nos preguntamos ¿por qué para este grupo, un factor aparentemente secundario como la vestimenta es lo primero que salta en el diálogo? Hace falta nuevamente, leer en el modo simbólico de la mujer andina, juntando varias de sus líneas de reflexión para atisbar posibles respuestas.

Si consideramos que no es posible pensar el ejercicio hegemónico de la modernidad sin procesos de homogenización, que dibujen a las sociedades a imagen y semejanza del modelo deseado por el poder, detrás de sus palabras se encuentra una resistencia silenciosa a la homogenización, uniformización y asimilación consustancial a este nuevo momento del capital.

La globalización uniforma, aplana, borra las distinciones, a la vez que dispersa. Se trata de ocupar territorios desplazando a sus originales posesionarios, establecer sistemas jurídicos que avalen esa ocupación, y desestructurar las relaciones productivas preexistentes, destruyendo la historia y tiempo de los lugares, estableciendo otra territorialidad.

La vestimenta es, entonces, la expresión de ese intento de anulación de las otredades, culturales y de género, que dotan de identidad a los territorios; esto es, sus gentes y sus tejidos de relaciones y saberes. A la vestimenta se suma la pérdida de la lengua materna: ni siquiera las mujeres mayores la hablan. Pero decimos intento, porque a contrapelo de todo este despojo cultural, todas las mujeres -incluso las más jóvenes- se autodefinieron como indígenas ${ }^{4} \mathrm{y}$ campesinas, reafirmando su opción por ser y estar en su lugar y con su identidad.

"Mis abuelitos ellos si son indígenas, una vez fui al centro de salud y preguntaron eso, me dieron las cinco opciones y yo dije "indigena" y el doctor me dijo "ipero. mijita usted sabe hablar kichwa?" yo le dije que no y él me dijo "iEntonces, usted no es indígena, es mestiza!". O si uno no se viste de centro o no sabe hablar quichua, igual no le ponen indígena. Y eso que mi abuelito usaba poncho sombrero y mi abuelita se vestía de centro, si yo quiero ser indigena no me dejan porque no sé hablar kichwa. Así que ahora para no entrar en discusión digo mestiza" (Cristina Toapanta, 28 años).

4 Es particularmente relevante esta autodefinición si consideramos que el último censo, que supuestamente aplicó la auto-definición como herramienta, registra una disminución tendenciosa de la población indígena. 
"Sí, nunca he de decir yo no. Esa es mi cultura porque mis padres no fueron unas personas que vivieron en el centro del pueblo, ellos vivieron aqui, porque voy a desconocer eso. Eso yo nunca cambiaré hasta cuando Dios me tenga" (Elena Alcocer, 63 años).

\section{"[...] indigena, porque más me siento del campo que de la ciudad” (Carmen Alcocer, 49 años).}

El acceso a más dinero efectivo y el poder tomar decisiones sobre el uso de ese dinero es otro de los cambios más sentidos a nivel personal. Tanto las mujeres mayores como las más jóvenes consideran que este ha sido un cambio positivo. Algunas incluso mencionaron que el ser autónomas económicamente, les ha dado la libertad de salir de relaciones afectivas abusivas pues no dependen de un "hombre que las mantenga". Todas las participantes concordaron que esta autonomía económica ha tenido un efecto en la dinámica familiar, pues las madres han tenido que apoyarse en otras personas para el cuidado de sus hijos durante las horas de trabajo. Un tema interesante para analizar con mayor profundidad a futuro es el aparente incremento de madres solteras en la zona. No fue fácil lograr ahondar en este tema, solo en una de las entrevistas realizadas luego a una mujer joven que trabaja en una florícola pudimos conversar sobre la necesidad que ella percibe de que las mujeres trabajadoras tengan acceso a servicios de educación y salud sexual y reproductiva. Ella nos comentó que las pocas brigadas existentes en la zona se dan en horas de trabajo por lo cual no pueden participar. "Por ejemplo, traen las brigadas de ginecología del Consejo Provincial pero traen entre semana de ocho de la mañana a cuatro y media de la tarde, cuando una está trabajando" (Paola Toapanta, 25 años).

\section{A nivel familiar}

El cambio más sentido por las mujeres que participaron en el taller con relación a la dinámica familiar, es la pérdida de la presencia de las madres en la vida de sus hijas e hijos. Pudimos escuchar el relato de una pareja de madre-hija, en el cual la madre reconocía que durante el tiempo que estuvo trabajando en las plantaciones fue su hija mayor quien se encargaba de cuidar a sus hermanos y alimentarlos. La hija contó su experiencia desde un entendimiento de que su madre tuvo que trabajar fuera de la casa para apoyar la economía del hogar y no lo resiente; sin embargo, ella es ahora una de las productoras que forman parte de la Feria Agroecológica y una de las ventajas que le ve a su ocupación es el poder alimentar a su familia de lo que produce y tener ingresos adicionales por la venta de los excedentes.

"[...] hemos podido sembrar estos frutales, siembro hortalizas, tengo también, bueno ahora si me he descuidado un poco, pero también tengo asi lo que es frejoles, maices en sistema escalonado. Para la alimentación para la casa. Poco así cuando me sobra, salgo así a vender al pueblo. No pertenezco a la feria porque el motivo del tiempo. Porque tengo a mis niños y mis hijas trabajan en las flores" (Laura Cuzco, 48 años).

En otros casos, son las hijas quienes trabajan en las plantaciones y se apoyan en sus madres para el cuidado y atención de sus niños y niñas. Existe un caso particular donde sus dos hijas trabajan en las florícolas, una de ellas deja sus hijos a cargo de la madre, y es la madre quien forma parte de la Feria Agroecológica. En esta unidad familiar los ingresos de las hijas ayudan a pagar la educación de sus propios hijos y los gastos de la casa familiar (luz, teléfono, etc.). En el caso de la hija soltera, le permite tener cierto nivel de ahorro. Sin embargo, no se percibió en la conversación el interés de las hijas por dejar su actividad en las plantaciones para apoyar la iniciativa productiva de la madre: "Que de las flores claro que también se contamina el cuerpo humano y todo el ambiente, pero también se trae la economía, el dinero para el hogar" (Maribel Guachamin, 28 años). 
Estos testimonios, ratifican el sinnúmero de documentos que enfatizan en este mecanismo violento e invisibilizado de dominación de clase y género, vinculado con la jornada laboral femenina:

\begin{abstract}
"Dado que desde el Estado no se han dictado políticas ni se han diseñado proyectos y progra $\neg$ mas para aliviar el trabajo doméstico, el trabajo reproductivo, vemos que esta creciente inserción en el ámbito laboral coloca a las mujeres en una situación de doble explotación. Así, sin mover la lógica machista que asigna a las mujeres las tareas del cuidado y reproducción de la vida, también se incorporan las jornadas laborales, fuera de la casa. Es necesario además mencionar la creciente cantidad de mujeres que tiene a su cargo la jefatura de hogar. De esta forma las mujeres terminan con jornadas extenuantes que implican, en promedio, para el sector rural 22 horas semanales de trabajo más que los hombres, como lo señala la encuesta de uso de tiempo" (Flores, 2011 en: Hidalgo y Laforge, 2011: 104).
\end{abstract}

En el taller pudimos mirar cómo la visión de su trabajo, se presenta entreverado con las condiciones materiales y subjetivas para producir: todas prefieren trabajar y vivir en el campo, la principal dificultad que enfrenta es el poco acceso al agua de riego para la producción. Una indica que antes era humillada por su esposo pero que eso ha cambiado. Todas tienen largas jornadas de trabajo, empiezan entre las 4 y 6 de la mañana y su jornada puede terminar entre las 8 y 10 de la noche.

Están de acuerdo con que el tiempo de las mujeres y hombres debería ser igualmente valioso, pero eso no parece ser cierto pues los hombres tienen la posibilidad de descansar y ellas no. En el espacio laboral de las plantaciones, describen asignaciones diferenciadas en las actividades, que atribuyen a características "biológicas"; así, los hombres realizan tareas de más fuerza física, mientras que las mujeres tienen más "delicadeza" para manipular las flores. Si bien reciben la misma paga (salario básico), concuerdan con el resto de mujeres que participaron en este estudio que los hombres tienen más posibilidades de descansar y por lo tanto su tiempo es más valorado Pese a que consideran que el trabajo de la mujer es más cansado, afirman que el trabajo del hombre es más valorado por ser más visible, y por ser quien trae el dinero a la casa.

Cuando las mujeres se refieren a su trabajo, construyen un discurso implícito detrás de sus palabras, un discurso que requiere atención para develar una narrativa del esfuerzo interminable, de condiciones difíciles, sea por la dureza del trabajo en la chakra, o por la culpa por la ausencia ante los hijos, o por la enajenación de su tiempo por el trabajo asalariado, o por la falta de condiciones favorables para alivianar la labor cultural (tierra, riego, crédito, tecnología) o por su larguísima jornada que empieza antes de salir el sol y termina cerca de la media noche, para poder completar los múltiples pendientes que les han sido socialmente asignados y que acatan sin cuestionar. Tan es así, que aun hablando de sus actividades "propias", las de su autorrealización -como la venta semanal y la organización de productoras agroecológicas-, esos tiempos no son detallados en el listado de actividades diarias. Y, sin embargo, como veremos, es esta actividad que les provee una identidad propia, la que constituye el germen de posibilidad de vida digna para sí mismas y sus hijas.

"Una de las virtudes de ser mujer es ser madre y tener el amor y el cariño de los hijos. Y nosotras
como mujeres nos encontramos en un entorno, con la fertilidad del suelo. O sea, el suelo es como
una mujer, la mujer puede ser madre, el suelo también, la tierra en si es fértil y también nos da sus
productos" (Jaqueline Lema, 40 años).

Se muestran orgullosas del aporte que brinda este titánico esfuerzo. Siendo tan medular ese factor limitante, no solo que no lo consideran un problema sino su fuente de dignificación y reconocimiento, en tanto consideran que sus aportes son fundamentales para sus comunidades 
como: cuidar de la familia, producir alimentos, participar en reuniones, motivar a las personas a producir agroecológicamente, entre otros. Señalan distintos roles importantes de la mujer en sus comunidades entre ellos: la crianza de los hijos, el cuidado de la alimentación, el resguardar y traspasar las costumbres y luchar por la equidad entre hombres y mujeres.

"Para nosotros más cansado. Como le digo a mi hijo, a veces yo hago alguna cosa por afuera y por adentro vuelta ya hay que hacer y otras veces hago por de dentro y ya vuelta por afuera esta botado. Más pendiente de todo, como le digo a veces mi esposo se queda, pero él no está preocupado de repente hacer el almuerzo a los hijos, al nieto. En cambio, uno corre para adentro a veces" (Carmen Alcocer, 49 años).

En suma, aunque lo primero que sale a colación son los cambios más aparentes, para el caso de nuestras mujeres, el cambio más significativo que sienten con la presencia de las flores, es la multiplicación de su jornada de trabajo, y con él, la pérdida de su bien más preciado: su tiempo; que es también la expresión de sus reductos de autonomía. Paradójicamente, su mecanismo de resistencia a este despojo vital es, la multiplicación de su jornada, la no renuncia al tiempo que permite la restitución de formas autónomas de existencia.

Las flores impactan en su cuerpo y su salud, lo saben, pero no encuentran opciones. En respuesta, lo que encontramos es la custodia de sus saberes domésticos y agrícolas, el uso del dinero como mecanismo de inversión y capitalización, la aceptación del empleo como estrategia temporal (aun cuando involucre décadas) del que saldrán a trabajar en sus parcelas para resolver por sus propios medios, su vida y la de los suyos. Para ello, mantienen sus labores agrícolas y van construyendo lentamente las condiciones favorables para dejar el trabajo asalariado.

En ese trayecto, en tanto su hacer recrea su saber, las mujeres resignifican aprendizajes y prácticas y las plasman en la casa y en la chakra, de modo que además de no morir, se reproducen y se muestran discretamente como alternativa para los otros (las otras) miembros de la familia. "Mi hijo se encarga de ver los animales. (El hijo de 44 años, era tornero en Quito, ahora vive con sus padres, cuida a los animales y ayuda a su madre en el trabajo del restaurante de Cayambe)" (Blanca Aurora Morocho, 63 años).

\section{Cambios a nivel de la comunidad}

La discusión con respecto a los cambios a nivel de comunidad, fueron plasmados en un dibujo (ver figura 1), se les pidió que en ese dibujo también se dibujen a ellas para poder identificar mejor su rol. En donde se resalta la presencia de la Iglesia, la plaza central -donde se venden gaseosas-, el reservorio de agua, la carretera "Panamericana", dos árboles y varias plantaciones. Las participantes decidieron titular a este dibujo "La Esperanza en destrucción". No hay personas dibujadas. Este dibujo se vuelve más significativo al ser comparado con el dibujo que realizaron mientras discutíamos sobre donde les gustaría estar en 30 años.

En un despliegue de esa expresividad simbólica, las mujeres nos muestran el impacto de las flores en su lugar:

- Una modernidad y un progreso sin gente, expresado en los servicios y la infraestructura;

- Un mayor consumo innecesario por efecto de mayor poder adquisitivo, simbolizado en las gaseosas;

- Una pérdida de verdor en el paisaje, menos chakras, menos bosques menos páramos;

- El agronegocio, que se "tragó" a la gente de La Esperanza.

- Las flores trajeron también, problemas sociales e inseguridad. 


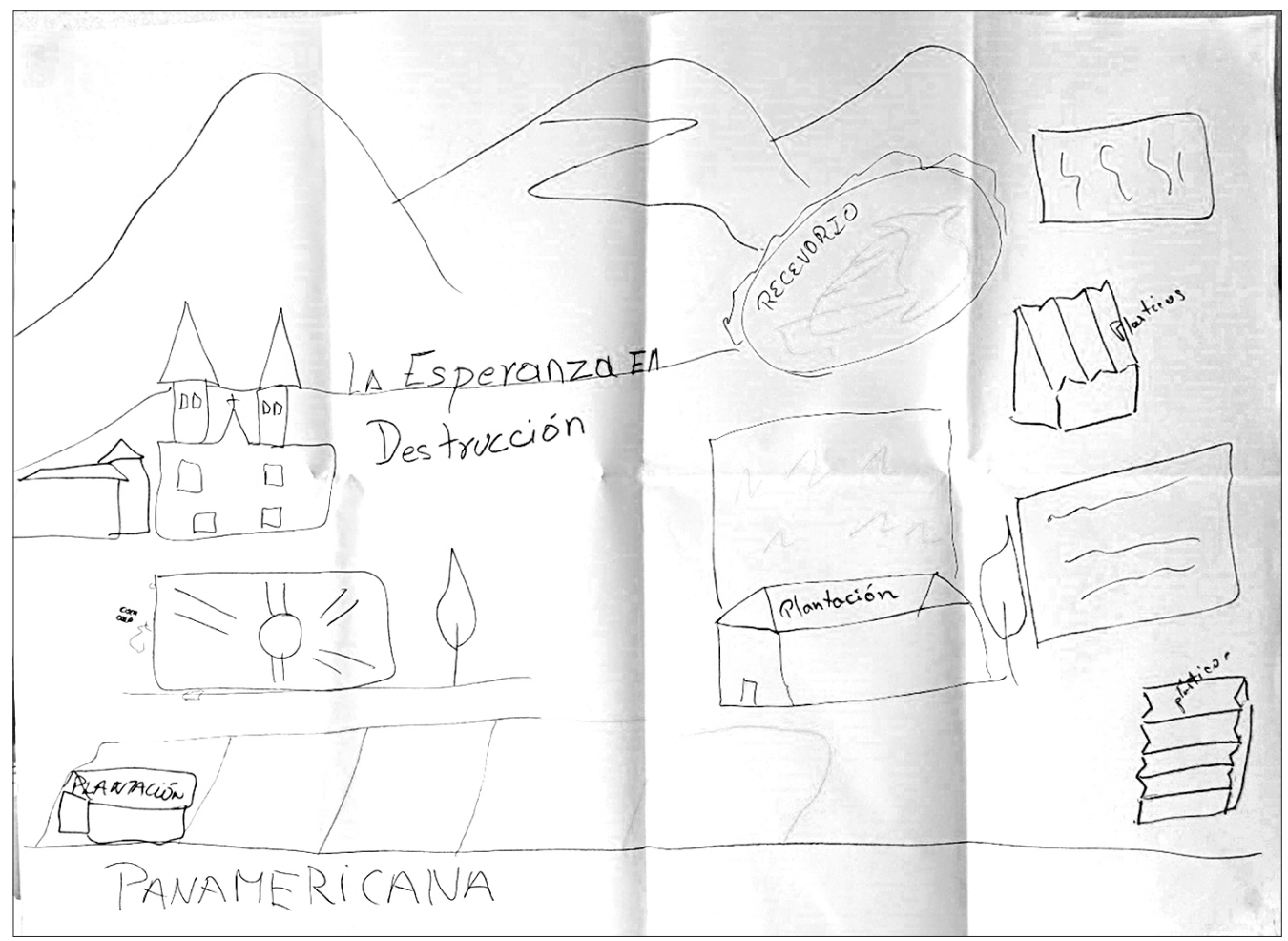

FiguRa 1. Dibujo de situación actual de La Esperanza

\section{Qué NO se ha llevado el agronegocio: Persistencias y re-significaciones en medio del desarrollo}

\section{Los saberes}

“...el crimen más grande del poder es el crimen de negar a la gente su identidad. El crimen de empujar a un pueblo a juzgarse a sí mismo mediante los criterios de sus opresores...”

John Berguer, 1972

Durante todo el proceso de diálogo con las compañeras de La Esperanza, nos percatamos de que las mujeres son custodias celosas de saberes, pero no lo saben.

En la sociedad que emerge desde la modernidad y el capitalismo, el espacio del saber es un espacio reservado, con puntos de referencia obligados y con coordenadas establecidas en las que se mueven aquellos que el sistema reconoce como detentadores del saber. Visto desde esta perspectiva, las mujeres quedarían fuera del ámbito del conocimiento reconocido socialmente. Por ello usamos el término saberes, en tanto se remite a un universo más vasto e interactuante, aun si no tiene reconocimiento:

"Es necesario distinguir los saberes comunitarios o locales de nuestra concepción 'occidental, profesionalizada' del conocimiento. El conocimiento en el sentido occidental es aquel que surge de la separación paulatina entre el trabajo y la vida cotidiana, en la medida en que el trabajo se parcializó y el conocimiento se alejó del ámbito de lo contingente en correspondencia tácita con esa parcialización de las actividades en las sociedades que tendían hacia la industrialización" (Vera, 1997). 
Este es el ámbito donde se mueven las mujeres, el del conocimiento negado o subalterno, que no obstante, es fundamental para la reproducción de la vida. Acaso por ser invisible (pero muy útil) a la imposición colonizadora, todavía constituye un espacio de producción, recreación y reproducción de los saberes.

Todas las mujeres entrevistadas consideran que el conocimiento más importante para el trabajo dentro de la casa es cocinar alimentos, trabajar la tierra, cuidar a los y las hijas y los valores familiares. Sus padres, especialmente las madres, son las que les compartieron este conocimiento. También para las mujeres más jóvenes, incluso aquellas vinculadas a las flores, el conocimiento más importante que tienen, es el saber de agricultura, criar animales, cuidar del hogar y la familia y los valores para mantener a la familia unida. Saberes adquiridos de sus madres y abuelas; y que, como veremos más adelante, constituyen su entendimiento del Sumak Kawsay.

"En la mañana ya es mi compromiso de mis animales, entonces ya tengo vuelta el horario para hacer el almuerzo, ya de ahí vuelta de ir a traer los animales, asegurar. De ahi ya vuelta otro horario para hacer la merienda. Mi mamita me ha enseñado hacer todo, a ella también así le deben haber enseñado por eso nos ha enseñado asi" (María Teresa Cuzco, 54 años).

Lo mismo mujeres de más edad, como las jóvenes destacan cualitativamente, -a diferencia de los conocimientos masculinos- mujeres tienen saberes para cuidar y sanar enfermedades: "Las mujeres sabemos curar, alimentar, producir y tenemos un sexto sentido."

Detrás de estos conocimientos escuetamente descritos, existe un cúmulo inmenso de saberes que involucran una cuidadosa observación, ensayo continuo, y la observancia de principios oralmente adquiridos.

Nos referimos a los tiempos de siembra, a la atención puesta a la luna, a las señas del entorno natural, al seguimiento atento de los ciclos agrarios, rituales y festivos. Estamos hablado de cuando sembrar, cómo sembrar, cómo cuidar y seleccionar la semilla que les fue heredada, cómo alimentar la ashpamama (la tierra de cultivo), cuándo y con qué. También de la decisión de qué sembrar, qué especies y variedades, cómo asociarlas. Qué plantas cuidar para que no se pierdan, cómo cuidarlas y qué usos tienen. Qué plantas curan o alivian qué males y cómo prepararlas (dosis, frecuencias, combinaciones). Cómo cuidar sus animales, cómo desparasitarlos, con qué alimentarlos, con qué curar sus distintos males. Saber intuir energías, estados de ánimo de plantas, animales y personas, en una conversación permanente, sin que medie la palabra.

"Cristina: para mí sí, pero creo que es biológicamente porque una mujer tiene que amamantar a su hijo y hay cosas como saber que el hijo esté enfermo sin que esté llorando. Paola: O también cuando el papá le ve al hijo no le pregunta qué le pasa porque le ve igual, en cambio la mamá sabe que algo le pasa al hijo. La mamá tiene ese instinto y ve la diferencia" (Cristina y Paola Toapanta, 28 y 25 años).

Esto no es poca cosa, se trata de una reproducción, recreación, afinamiento, y contextualización sistemáticos que operan en un continuum experiencial que tiene milenios, con resultados bastante exitosos en términos de productividad, sustentabilidad, soberanía alimentaria, eficiencia y eficacia. Y es en los territorios de mayor ocupación del capital, donde las mujeres sostienen y persisten en este saber.

Nada de esto fue detallado en los talleres, tampoco se verbalizó en las entrevistas; lo pudimos observar porque lo hacían mientras conversamos en sus casas y sus chakras. Y esto se explica solo cuando nos colocamos en el lenguaje del saber campesino -para este caso andino-, que se custodia mejor entre las mujeres, acaso porque se trata de un ámbito despatriarcalizado.

Los saberes en el mundo andino son simbólicos, culturales, generados y compartidos por la comunidad. Nadie es propietario. No se enseñan, sino que se "muestran", pues se trata de un saber práctico concreto que se realiza en la vida comunitaria, que se aprende recreándolo en la 
práctica. El aprendizaje se lo realiza en la vida misma, no hay una intencionalidad exclusivamente racional, ni persona que detente la figura de maestro. (Vogliano y Vallejo, 2012).

Este entendimiento/vivencia del mundo, no experimenta la dislocación trabajo intelectual/ trabajo manual, ambos procesos ocurren al tiempo y de ello deriva el aprendizaje, la experiencia, la producción material y de saber.

"A diferencia del conocimiento técnico-científico, que se caracteriza por ser universalizador, cerebral, impersonal/desencarnado, articulado/explícito, resultado de la aplicación de un método, teórico y poner en oposición al sujeto del objeto; el saber andino es local/contextual, sensorial/ emocional, encarnado en el ayllu ${ }^{5}$, implícito/holístico, vivencial, se circunscribe a la circunstancia inmediata y dado que se produce en el proceso mismo de la crianza, maneja múltiples vías de acceso" (Ishizawa, 2008: 10).

Sobre la base de este saber, las mujeres han venido incorporando y resignificando conocimientos y habilidades adquiridas (o impuestas) desde los requerimientos del capital. Ya sea habilidades culinarias en sus trabajos como domésticas, para el caso de la experiencia de las mujeres mayores; ya sea en la escuela o en las mismas plantaciones, entre las más jóvenes, donde han aprendido destrezas sociales, o técnicas (en el caso de las flores) e incluso han identificado nuevas necesidades de aprendizaje (alguna mencionó la importancia de aprender inglés).

Estas nuevas necesidades las resuelven participando en la oferta del desarrollo, a través de capacitaciones para el perfeccionamiento de habilidades manuales: tejido, costura, peluquería, artesanía; o el afianzamiento de conocimientos administrativos, técnicos agrícolas y pecuarias, donde descubren la agroecología, como la posibilidad de reconocer su propio modo de hacer agricultura, mejorándolo y complementándolo. La escuela, a pesar de ser también un ámbito de colonización, constituye al mismo tiempo un cambio favorable, emancipador y enriquecedor para las mujeres.

\section{La crianza de la chakra: esa relación cuidadosa con la naturaleza, una cosmovisión, un enclave de resistencia.}

Nuestra conversación con las mujeres, nos condujo a reflexionar sobre un espectro diverso de temas que nos aproximaron a sus percepciones sobre la naturaleza, las relaciones sociales comunitarias, la solidaridad, su visión de la ciudad y del campo, el buen vivir, entre las más importantes. Toda esa variedad temática confluía directamente en lo que llamamos cosmovisión. Miramos no sin cierto asombro, lo fuerte y arraigada que resultaba, aún a pesar de ese aparente dominio del discurso modernizante y del paisaje inundado de invernaderos y devastación.

A contrapelo de la impronta de las flores en el territorio y las gentes, las compañeras de La Esperanza, mantienen un habitus andino, mucho más indeleble que la huella del capital, aún entre el grupo de jornaleras, aún entre las más jóvenes, con la sola excepción de una mujer que no tiene ningún vínculo con la tierra y la producción agrícola; quien, sin embargo, sueña a futuro poder retirarse y tener una chakra donde producir su alimento.

Frente a la contaminación del entorno y la producción sin precedentes de basura y desechos que ellas presencian con las flores en la zona, todas las mujeres entrevistadas consideran que es importante cuidar la naturaleza y lo principal es no contaminarla.

5 El ayllu es la unidad de la estructura social comunitaria, es la familia ampliada (característica de las culturas agrarias), que incluye parentescos simbólicos y rituales, la comuna kichwa es el gran ayllu local. Pero la concepción más profunda incluye también los elementos naturales, todos dotados de ánima: la madre tierra (ashpa mama) la hermana/ madre semilla (muruñaña), la madre agua (yacumama), los abuelos montes (apus). Que se mantienen vigentes en las formas de relacionamiento campesino, aunque estas no se expresen verbalmente o de forma racionalizada. 
Ellas identifican a la agroecología como el "nuevo" sistema de producción que no solo cuida la naturaleza sino también que permite lograr la soberanía alimentaria. Para eso ellas están protegiendo el suelo, conservando su páramo, usando adecuadamente el agua y produciendo agroecológicamente.

Como dijimos, valoran la agroecología porque pone en valor su saber agrícola tradicional y lo proyecta hacia un nuevo momento que les permite producir y comercializar para garantizar su vida en condiciones autónomas y dignas.

\begin{abstract}
"Me siento mejor porque antes como que más nos ignoraban, sino había, salíamos a trabajar en las plantaciones, no había la manera de desenvolvernos como mujeres. Ahora de esto que salió del grupo de mujeres de hacer las hortalizas y todo. Entonces me siento más, sé que puedo desenvolverme económicamente y todo eso y hasta no me siento humillada por mi esposo, porque antes si me humillaba, entonces sí, entonces me siento bastante bien" (Laura Cuzco, 48 años).
\end{abstract}

Todas indican que es importante cuidar la naturaleza y para eso es importante enseñarles a los hijos a cuidarla y no botar basura, una de ellas expresa que en su trabajo lo único que hacen es producir basura: "En mi trabajo no hago nada para cuidar la naturaleza porque hay produzco basura y pongo químicos todo el día, pero el mundo es así. Si el mundo no comprara flores y no tendría que hacer esas cosas (Cristina Toapanta, 28 años).

La "crianza mutua con la chacka", es la expresión implícita y a la vez tangible de esa unidad holística entre cosmovisión y acción. Es esa simultaneidad entre lo concreto, local, circunstancial, ritual y relacional, con lo abstracto, universal, simbólico, mítico y sagrado. No está exenta de método y rigurosidad que le son propios, apela a la observación atenta pero también, a la escucha, a la intuición, a la percepción y al afecto, como herramientas de aproximación a la realidad.

Siguiendo a Julio Valladolid (2001), la agro-crianza andina, entendida como esa totalidad holística que hemos venido remarcando, es una "manera respetuosa de vivenciar la naturaleza, cuya característica más distintiva, es la de ser criadora de diversidad, diversidad que conviene al fluir de la vida, con bienestar cultural.

A pesar de la modernidad impuesta, donde se individualiza y dispersa a las personas, este modo de vida agrocéntrico permite mantener un tejido de relaciones comunitarias, basadas en la solidaridad, la reciprocidad y la ayuda mutua. Las flores no lograron desestructurar los sistemas de prestamanos para colaborar en los momentos de más trabajo en la chakra, que se reciprocan con la entrega posterior de una parte de la cosecha. Todas las mujeres ven que la minga, trabajo comunitario no remunerado para beneficio de todos y todas, se mantiene y reproduce permanentemente. Tampoco se ha perdido el auxilio entre comuneras y comuneros cuando alguien enferma o muere y que expresa la cercanía y confianza principalmente entre las mujeres. Ese apoyo permanente, incondicional y cotidiano cuando se trata de ayudar a cuidar a los hijos e hijas, en las siembras, en los intercambios de comidas y en la posibilidad de conversar y acompañarse cuando se sienten solas. Todo eso es parte viva y en resistencia, de una cosmovisión que se resiste al aislamiento, individualización, monetarización, ciudadanización de las relaciones. Una de las entrevistadas señaló que la solidaridad en el campo es "es lo que más nos construye”.

En este punto se marca una diferencia entre las mujeres entrevistadas y la única señora que no forma parte de la Feria Agroecológica -trabaja como apoyo administrativo en la Tenencia Política-. Ella dice que no existe solidaridad, ni siquiera entre las mujeres. Es ella quien señala que cuando vivía en la ciudad se sentía sola. Ella encarna el efecto devastador del capitalismo cuando invade y privatiza las relaciones.

6 Para el pensamiento andino, no existe un equivalente epistemológico para la noción cartesiana de sujeto: las personas no son sujetos que conocen y dominan los objetos del universo. En tal sentido, las personas en su quehacer agrario, no "manejan" el ganado, el suelo, o la semilla. Los crían, esto es, los cuidan, enseñan y aprenden de ellos, en un cuidado semejante en todo sentido a criar los hijos o cuidar de los/as hermanos/as o padres/madres, porque necesitan de los cuidados de estos para existir. No ejercen dominio sobre ningún elemento del cosmos, se crían mutuamente. 


\section{Campo o ciudad}

Un aspecto que nos llamó mucho la atención, es la opción generalizada por el campo como lugar de vida. A pesar del discurso modernizador que el capitalismo ha instalado en el campo, donde la ciudad es el modelo de vida y el lugar anhelado. Todas las mujeres, particularmente las mayores afirman que es mejor vivir en el campo porque están más tranquilas y libres, todas indican que lo mejor de vivir en el campo es la libertad, la posibilidad de producir sus propios alimentos y que no se requiere comprar todo. Además, que los niños y niñas tienen la posibilidad de crecer con más libertar y aire puro.

Para las más jóvenes, en la ciudad hay mejores servicios básicos y que el trabajo de las mujeres de la ciudad es menos pesado. Sin embargo, prefieren el campo por el aire libre, la libertad y porque los niños y niñas pueden jugar libremente. Consideran que la principal diferencia entre las mujeres del campo y la ciudad es que el trabajo de las mujeres urbanas es más de "papeleos". El campo, entendido como su lugar, su quehacer, su saber y sus relaciones, es sinónimo de libertad, autonomía y soberanía alimentaria. Por ello, ni siquiera los servicios mejores y el trabajo más liviano, pueden reemplazar los preciados bienes de los que están conscientes de gozar.

\section{Economía, justicia y Sumak Kawsay}

Para todas las mujeres entrevistadas la economía es sinónimo de dinero. Sin embargo, tras de esas respuestas vienen algunas reflexiones que dan cuenta de su percepción más amplia, menos de la ideología capitalista, sobre todo cuando describen cuál sería para ellas una economía "justa". Para las mayores, una economía justa se logra cuando reciben un precio justo por sus productos, cuando tienen tierra y agua suficiente para producir, y animales para criar. Y complementando, las más jóvenes consideran que una economía justa es tener trabajo, ser solidarias y sembrar la comida. Una de las mujeres indicó que la economía justa es "que todos estén bien, pero a su manera". Para las mujeres que trabajan en las flores, una economía justa seria si se pueden compartir los gastos y tareas del hogar y recibir un buen salario. Se nota aquí ya, la influencia que sobre ellas ejerce la relación de sujeción capital/trabajo; pero también, se explicita la demanda de mejor distribución de las actividades reproductivas, como hecho económico.

Las compañeras completan sus reflexiones concluyendo que la economía no es siempre justa, de hecho, casi nunca lo es. Por ello la necesidad de darle este adjetivo, para explicar mejor una condición que no ocurre plenamente en su realidad, pero que permanentemente están trabajando para que se produzca; porque con ello alcanzan una vida digna y un buen vivir, que consistiría en tener alimentación, salud, estar bien y en armonía en la familia y tener trabajo para pagar servicios básicos. Una de ellas indicó que su trabajo en la florícola no es tener una vida digna o buen vivir.

El buen vivir se logra cuando todos tienen un trabajo honrado, una buena relación con la familia y acceso a una buena alimentación; pero también "cuando somos más autónomas, unidas y nos apoyamos los unos a los otros”. Donde nadie tenga menos, pero tampoco de más. El Sumak Kawsay o vida digna fue definido por una de las entrevistadas como: "creo que tener todo tampoco es digno. Yo tengo una vida digna porque disfruto de mi familia, de lo que yo tengo...".

\section{El modelo productivo en sus territorios.}

Al ser preguntadas sobre qué opinan del sistema productivo actual, se produce nuevamente apreciaciones diferenciadas pero complementarias, que surgen de su lugar concreto de trabajo y producción. 
Las agricultoras autónomas señalan que la agroecología es el nuevo sistema productivo. Este sistema les permite la soberanía alimentaria, organizarse para planificar la siembra para atender las demandas del mercado, no usar químicos y producir en espacios más reducidos que los que tenían sus antecesoras.

Para el grupo de entrevistadas asalariadas, el modelo actual de producción son las florícolas (agroindustria) y que es altamente contaminante. Tienen claro que su presencia es determinante para toda la economía local, no solo de quienes trabajan en ellas, sino de quienes les proveen bienes y servicios. Saben que esta industria alcanzó su pico más alto, y empieza su declive, lo que representa una amenaza para las familias en el territorio, pues no existen ofertas alternativas, salvo la producción autónoma y sus obstáculos (poco mercado, precios bajos, inexistencia de crédito, poco o nulo acceso a tierra y agua).

\section{Construyendo el futuro: Autonomía, Comunidad y Buen vivir}

Las mujeres de La Esperanza hacen honor al nombre de su lugar. Como hemos visto en sus testimonios, a pesar de la fuerza impositiva del capital en sus territorios y en sus vidas, la persistencia en mantener sus saberes y sus relaciones comunitarias, el acceso a la tierra por limitado que este sea- junto con su apuesta por una agricultura para la vida y la soberanía alimentaria; su confianza en la organización y su proyecto, nos transmiten una perspectiva esperanzadora del futuro que ellas mismas se están construyendo. De eso están conscientes, de que sus esfuerzos construyen paso a paso una autonomía soñada para sí mismas y para sus hijas/os.

Tienen claro su proyecto de futuro, porque a pesar de la negación del poder, lo están construyendo con sus propios recursos y con su mucho trabajo. Como dice una de las compañeras: se requiere de "sacrificios para que los hijos tengan un mejor futuro".

Aunque no abundan en detalles, su organización de productoras es su espacio de planeación, de proyección de fortalecimiento de capacidades, conocimientos y poder. Mientras la producción agroecológica junto a la comercialización cercana y directa en su feria, es su propuesta de futuro autónomo.

Una vez más, recurrimos al dibujo para que puedan plasmar de manera más cómoda, sus proyectos y sueños de futuro. Proyectos que son de comunidad, de colectivo y de resistencia frente al proyecto capitalista que se impone en su territorio.

Lo primero que se nota en el dibujo de la situación futura es la ausencia de plantaciones de flores en la zona y de la Iglesia. Estas han sido sustituidas por negocios propios y comunitarios de: turismo rural, alimentación, artesanías y un centro de acopio comunitario que recoge la producción de frutas y hortalizas de las familias para su exportación. Resalta la presencia de más árboles y un sistema de riego comunitario que permite que más familias tengan acceso a agua para sus parcelas. En la discusión las mujeres participantes indicaron que esperan que en el futuro más familias tengan acceso a tierra y agua para la agricultura familiar. Tiene un espacio importante en el dibujo un parque para que los niños y niñas de la comunidad jueguen.

En este ejercicio fue más fácil para las participantes identificar lo que ellas pueden hacer y se nota la presencia de muchas personas en los negocios, el parque y de turistas llegando a la comunidad. Una niña que participo del taller se animó a tomar el marcador para dibujar las sonrisas en las caras de las personas, aunque no se logra identificar bien cuales son mujeres. Las participantes titularon este dibujo "La Esperanza, llena de luz, progreso limpia y segura" (ver figura 2) lo cual nos permite identificar que:

1. La idea de progreso de las mujeres participantes está vinculada a la idea de generar recursos económicos y tener más acceso a efectivo, pero a través de actividades colectivas y que aprovechen los recursos naturales existentes sin agotarlos. Además, se nota que identifican actividades para agregar valor a la materia prima que están muy cercanas a sus conocimientos e intereses (cocinar alimentos típicos y tejer o confeccionar artesanías). 


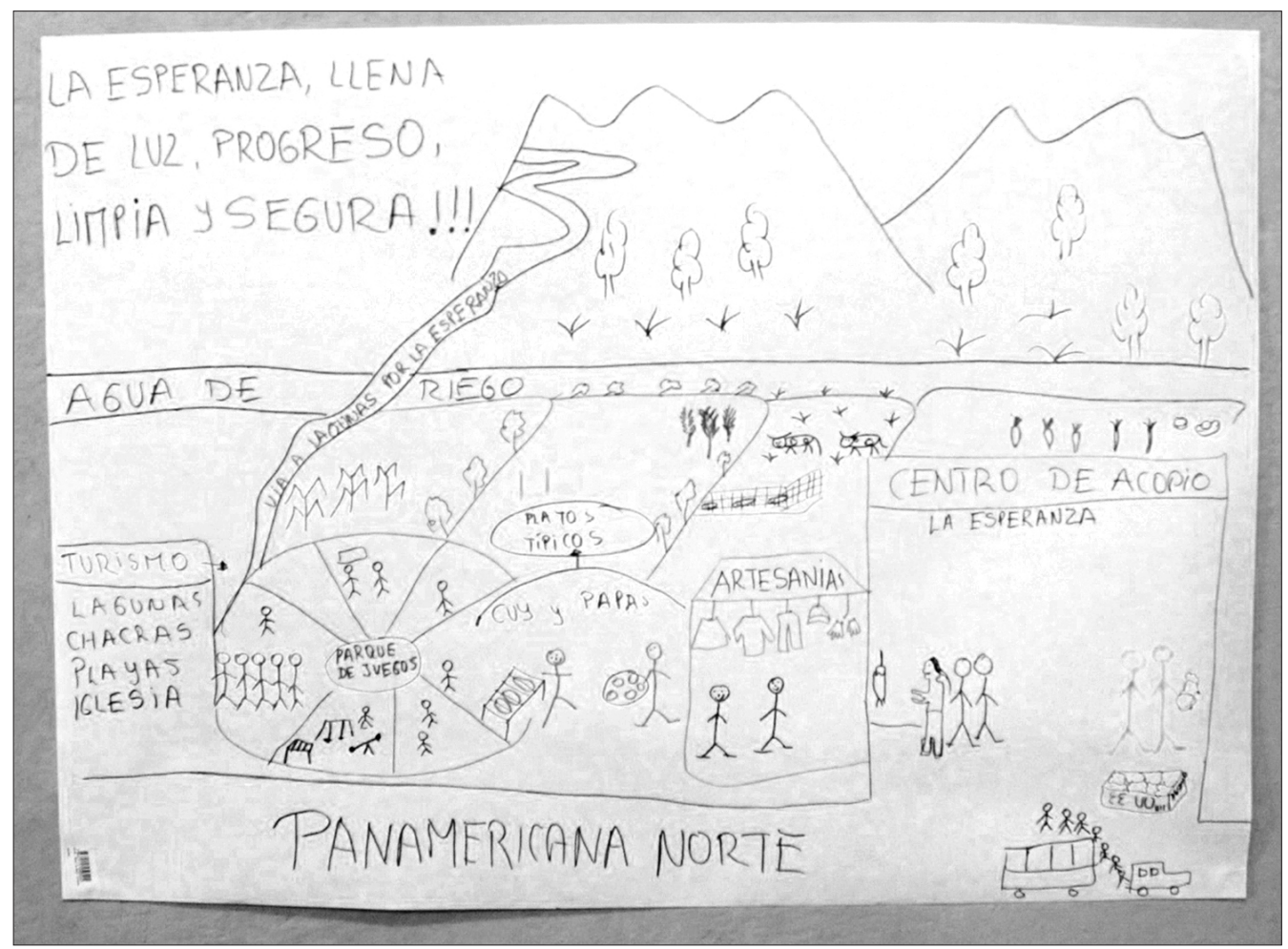

FIGURA 2. ¿Cómo queremos que Sea La Esperanza en el futuro?

2. Si bien no lo mencionaron antes, la presencia de las plantaciones está generando desechos y contaminación. La ausencia de árboles, ríos y animales en el primer dibujo contrasta con lo "lleno" que esta este segundo dibujo de vida y como se aprovechan todos los espacios posibles.

3. El tema de la seguridad es de mucho interés para las mujeres participantes, muchas han indicado el aumento de actos delictivos en sus comunidades y las dificultades que tienen para salir de sus casas y dejar a sus animales y bienes vulnerables al robo.

\section{Conclusiones}

Si bien, las mujeres de La Esperanza no han sido ajenas a procesos de capacitación -principalmente técnica-, es evidente, en este breve encuentro, que hace mucha falta un acompañamiento que suscite reflexiones políticas desde una perspectiva de género, clase y etnia. Es claro, que el desarrollo con su tecnocracia, ha trabajado con las mujeres, desde la sola circunstancia de que son ellas a quienes encuentran en el campo.

Sus reflexiones y acciones muestran claramente una intuición que resignifica y torna persistentes unos saberes no nombrados, invisibilizados, pero presentes. Saberes, cuya potencia emancipadora, no se logra atisbar.

El sistema dominante, que ha ocupado sus territorios en al menos las últimas tres décadas, ha orillado a las familias, pero principalmente a las mujeres a la búsqueda de ingresos, no solo como aporte a una economía familiar cada vez más precaria, sino como un mecanismo (el mecanismo autorizado por el propio sistema) de dignificar su rol menospreciado y sojuzgado en los entornos más íntimos y subjetivos de sus vidas: sus relaciones de pareja, familiares y comunitarias. 
El precio de esta opción han sido nuevas modalidades de descalificación y culpabilización. Un ciclo que las juzgaba por improductivas y ahora las juzga por abandono de hogar y adopción de costumbres liberales. Circuito en el que, siendo víctimas y sintiendo el peso de ese juzgamiento, al mismo tiempo se convierten, como es usual en estos casos, en sus primeros verdugos. Es claro, que queda fuera de todo foco de análisis, la sola posibilidad de compartir responsabilidades de cuidado que compensen esos tiempos fuera del espacio doméstico.

El espacio de interacción resultó muy breve; quedaron en carpeta conversaciones, dibujos, comidas junto al fogón en donde se redescubran, develen y proyecten esos saberes no dichos, no explicitados, de múltiples aspectos: agricultura, identidad, medicina, maternidad, ecología, cuidados, culinaria, nutrición, confección, estética corporal, sexualidad, de entre las que pudimos vislumbrar brevemente en las entrevistas y talleres. Conversar sobre esos saberes tiene una importancia política medular y merece generar espacios para ello.

Existe una avidez por dar continuidad a lo iniciado, fortalecer capacidades de participación que les permita con propia voz, incidir en sus casas y organizaciones comunitarias primero, y luego en sus espacios locales, posicionando sus demandas específicas, mismas que por ahora son sentidas, pero aún requieren ser modeladas en clave de planteamientos políticos.

Creemos que el proceso metodológico propuesto, es sensible a recuperar los otros lenguajes, intuitivos, sensitivos, prácticos, gráficos con los que las mujeres campesinas se expresan con más facilidad; sin embargo, su límite radica en el breve espacio en el que se generó. Sería importante encontrar espacios y apoyos que favorezcan un proceso más continuo y sistemático, que permita recuperar con más detalle esta memoria histórica que, como hemos señalado, tiene un cúmulo de aristas por desovillar. La exploración de los otros lenguajes, aplicada en procesos sostenidos puede favorecer una expresión más libre de pensamientos y sentimientos que inundan a las mujeres y que cuentan con pocas posibilidades de expresarse.

En sus reflexiones finales, las mujeres concuerdan en que requieren que las autoridades asuman un rol más decidido en el apoyo a la producción agroecológica para contar con capacitación, caminos, abonos, acceso a agua de riego suficiente y que las autoridades compren y promocionen los productos agroecológicos. Saben (aunque no se animan todavía) que necesitan construir liderazgos femeninos que participen directamente de los espacios de decisión organizativos y de gestión pública local, solo así podrán posicionar sus demandas específicas, y poner su perspectiva en las demandas compartidas como las productivas.

Todas consideran que requieren de más apoyo para talleres. Dicen que es importante hacer que los y las jóvenes se preparen y les guste el campo. Las mujeres más jóvenes encuentran necesario contar con espacios de formación que les permita asumir liderazgos; les gustaría mucho poder intercambiar experiencias con otras jóvenes del campo y la ciudad, para ampliar sus horizontes.

Para ninguna de las compañeras participantes, la ciudad es un anhelo por alcanzar; al contrario, la necesidad recurrente es la de tener opciones de empleo o de ingreso que les permita seguir en el campo.

Creen que en el futuro tendrán que seguir trabajando para no depender de nadie, una indica que deberían regular las florícolas para que no haya más. Incluso la señora que no trabaja en la agricultura dice que en el futuro le gustaría trabajar su terreno para producir alimentos.

$\mathrm{Su}$ futuro es, como toda su cosmovisión, un eterno retorno a la tierra como fuente nutricia de la vida. 


\section{Bibliografía}

Agudo, Ximena. 2000, Tiempo, espacio y poder: las claves metadiscursivas del desarrollo sustentable, disertación preparada para el Encuentro de la Asociación de Estudios Latinoamericanos, Miami, marzo, versión en línea.

Altamirano, María Isabel et al. 2013, “Soberanía Alimentaria, trabajo y soberanía del cuerpo...”, en: IEE y ONU, Mujeres, Soberanía Alimentaria y Mujeres, Asamblea de Mujeres populares y diversas, IEE, Quito.

Brassel, Frank et al. (Eds.) 2008, ¿Reforma Agraria en el Ecuador?: viejos temas, nuevos argumentos, SIPAE.

Breilh, Jaime. 2005, "La Floricultura y el dilema de la salud: Por una flor justa y ecológica", en: Informe Alternativo sobre la Salud en América Latina, Observatorio Latinoamericano de Salud. Centro de Estudios y Asesoría en Salud, CEAS, Quito, pp. 70-83.

Céspedes, Janet e Ivonne, Pachacama. 2012, Situación socio económica de la Parroquia la Esperanza del Cantón Pedro Moncayo, Provincia de Pichincha sobre la base de cadena corta, Tesis de Economía, Universidad Central del Ecuador, Quito-Ecuador, mimeo.

Flores, Judith. 2011, "Tierra y mujeres, un problema económico y sexual”, en: Hidalgo, Francisco y Michel, Laforge (Eds.) Tierra Urgente, SIPAE, Quito.

Izhizawa, Jorge. 2009, "Notas para una epistemología de la afirmación cultural en los andes centrales", en Epistemologías en la educación intercultural, Memorias del taller sobre educación intercultural y epistemologías emergentes, PRATEC Proyecto andino de tecnologías campesinas, Cusco, Perú.

Lander, Edgardo, 2000, "Ciencias sociales: saberes coloniales y eurocéntrico", en: Lander, Edgardo (Comp.) La colonialidad del saber: eurocentrismo y ciencias sociales. Perspectivas Latinoamericanas, CLACSO, Buenos Aires, documento .en línea: http://bibliotecavirtual.clacso.org.ar/ar/libros/lander/.rtf

Larrea, Carlos. 2001, Hacia un análisis ecológico de la Historia del Ecuador: Hipótesis y propuestas preliminares, ECOCIENCIA, Quito, mimeo.

Ospina, Pablo. 2003, "Esquemas para una breve historia del espacio ecuatoriano", en: Camaren e IEE (Comps.) Historia del Espacio Módulo 2, Curso de Desarrollo Local con Énfasis en Manejo de los Recursos Naturales, Quito, mimeo.

Valladolid, Julio. 2001, Crianza de la Agrobiodiversidad en los Andes del Perú, Serie kawsay Mama, PRATEC, Lima-Perú.

Vera Herrera, Ramón. 1997, "La Noche Estrellada (la formación de constelaciones de saber)", en: Revista Chiapas, No 5, (ERA-IIEc), México.

Vogliano, María Soledad y María Fernanda, Vallejo Aristizábal. 2012, "Insurgir en el ombligo de la bestia'. Reexistencia y descolonialidad en el seno del desarrollo", en: Reyes, Eloy Alfaro et al. (Comps.) Naturaleza y Cultura en América Latina. Escenarios para un modelo de desarrollo no civilizatorio, Memorias del XVIII Foro de Estudiantes Latinoamericanos de Antropología y Arqueología - FELAA. Quito, 17-23 de julio del 2011, Abya-Yala, Quito, pp. 203-228. 